\title{
HISTÓRIA DA ESCOLA E SUA INTERDEPENDÊNCIA COM A HISTÓRIA DO BAIRRO
}

Ana Paula Ferreira ${ }^{1}$

Ana Maria Brochado de Mendonça Chaves ${ }^{2}$

\section{INTRODUÇÃO}

A escola estadual professor José Castro de Araújo, situada no município de Poços de Caldas (MG), fará aniversário em novembro deste ano completando 33 anos. Sua história se entrecruza com a história do bairro, constituído para abrigar moradores de baixa renda que adquiriram suas casas através do parcelamento no modelo Conjunto Habitacional (COHAB). Com a pesquisa, busca-se situar a escola e o bairro como lugares de memória, documentos vivos, percebendo essa interdependência entre escola e bairro e o tempo histórico, tendo em vista fontes materiais e imateriais, no relato dos primeiros moradores e primeiros estudantes, refletindo sobre mudanças, lembranças e a importância da escola para a comunidade escolar atual. A presente pesquisa, em desenvolvimento, e sob a perspectiva da história-cultural, objetiva problematizar a formação do bairro e sua história concatenada com a história da escola, delineando ranços e avanços dessas transformações.

\section{METODOLOGIA}

No percurso metodológico, documentos e jornais da época são utilizados como fontes escritas. Compreendendo que somente essas fontes não escrevem o passado, utilizam-se também os registros orais na intenção de se perceber lembranças e detalhes que extrapolam a fixidez do documento escrito. Essa história oral tem sido captada e para isso, são valoradas as vozes daqueles

\footnotetext{
${ }^{1}$ Mestranda Universidade Federal de Alfenas (Unifal) e supervisora pedagógica do Estado de Minas Gerais. Endereço eletrônico: anapaulakarenina@yahoo.com.br

${ }^{2}$ Docente na Universidade do Estado de Minas Gerais (UEMG) e Pontifícia Universidade Católica de Minas Gerais (PUCMinas - Poços de Caldas). Endereço eletrônico: ambmchaves1@uol.com.br
} 
que fizeram parte desde o início da construção do bairro e a dos novos moradores na relação sujeito, memória e espaço. A memória antiga é recuperada tendo por base um questionário e entrevistas. $O$ primeiro foi elaborado pelas pesquisadoras $\mathrm{e}$ realizado pelos estudantes de $4^{\circ}$ ano com 16 moradores antigos do bairro. Os dados desses questionários são confrontados com as entrevistas que as pesquisadoras fizeram com oito primeiros moradores do bairro e quatro antigas funcionárias da escola, e também com uma ex-aluna. Os temas giram em torno da formação do espaço, eventos marcantes, relação entre os sujeitos, estrutura física, dentre outros pontos. Para delinear impressões na perspectiva atual, os mesmos alunos de $4^{\circ}$ ano responderam um questionário a respeito de como percebem o bairro e a escola.

\section{O BAIRRO}

Antes de atermos a história do Conjunto Habitacional (também conhecido como Casas Populares), faz-se importante contextualizar brevemente a formação da cidade de Poços de Caldas, de modo a compreendermos a divisão do espaço geográfico de acordo com as forças econômicas e políticas.

O nome "Poços de Caldas" está relacionado à sua característica de águas termais (do latim callidas - quente) e tendo em vista a grande procura por cura de doenças cutâneas ou respiratórias, a região passou a receber uma crescente demanda de turistas em busca de tratamento, ainda no século XIX. Vários investimentos privados e estatais foram realizados de modo a se criar um ambiente confortável e convidativo para os turistas e não foram medidos esforços para tal objetivo, construindo-se grandes hotéis, balneários, teatros, praças, cassinos.

Assim como historicamente a produção historiográfica se ocupou fortemente da história de quem ocupa o poder, das lideranças, de uma elite econômica e cultural, na cidade de Poços de Caldas isso não foi diferente. A história contada descreve prioritariamente fatos e memórias das famílias com grande poder político e financeiro, além de se ater ao centro da cidade (MEGALE, 1990; FERREIRA, 1996). O grupo com história registrada na maior parte das produções é a classe dominante e o espaço selecionado é o espaço onde esse grupo participa.

Assim, é muito comum a divulgação histórica no museu da cidade, nos nomes dos patrimônios públicos e no registro escrito, a presença do nome da família "Junqueira". Trata-se de uma família de sesmeiros que qualificaram a região como 
propícia para as pastagens e investiram na influência política junto ao Governo da Capitania de Minas Gerais para garantirem a posse da área.

Negligenciaram os Governadores das Capitanias de São Paulo e de Minas Gerais. O Capitão General de Minas Gerais concedeu Sesmarias nessa região litigiosa, contrariava o Aviso Régio de 27 de outubro de 1820 que proibia o estabelecimento de fazendas nessas circunstâncias. Não obstante, aos 7 de dezembro de 1820, o Juiz das Sesmarias e Demarcação da Campanha, Doutor em medicina, Faustino José de Azevedo, expediu a sentença cível de sesmaria, e demarcou a de uma légua em quadra que fora concedida aos 23 de julho de 1819 a José Bernardo da Costa Junqueira. [...]. Desse modo demarcado, a sesmaria abrangeu todo o Campo das Caldas. Levantada a questão da legitimidade, os Governos negligenciaram novamente, e com o decorrer do tempo os sesmeiros tornaram-se posseiros. (OTTONI, 1960 apud SOUZA, 2015, p. 51)

A área, em meados do século XIX, já despertava atenção não somente dos enfermos como também de agropecuaristas. Como se tratava de um espaço com demandas de utilização pública houve uma pressão da Província de Minas de Gerais em desapropriar os terrenos. Antes que isso ocorresse, Joaquim Bernardes da Costa Junqueira doou à Província 96 hectares de terra em torno dos poços de águas termais e sulfurosas, evento documentado no dia 6 de novembro de 1872 . Desde então, vários são as obras e espaços que recebem o nome de algum membro de tal família, como o bairro "Conjunto Habitacional", objeto de nosso estudo, denominado "Pedro Afonso Junqueira".

Em 23 de agosto de $1981^{3}$ aconteceu a entrega das chaves das 1553 casas aos moradores do bairro. Eram casas de 46 metros quadrados, todas brancas, de telha de fibrocimento, padronizadas. As ruas eram de terra e a presença do barro uma constante. Com objetivo de evitar chacotas e humilhações, os moradores colocavam saquinhos nos calçados para entrar no ônibus que os levava até o centro da cidade, e assim chegar com os sapatos limpos - é importante frisar que o bairro para trabalhadores e o centro da cidade se distancia em sete quilômetros. Hoje, com todas as inovações de transporte e investimento nas vias públicas esse trajeto parece ser curto, mas na época essa distância se alargava pela ausência de ônibus. As conduções eram precárias, e não alcançavam todas as ruas do bairro, fazendo parte da lembrança de muitos moradores antigos que em períodos de chuva o ônibus não adentrava o bairro, tendo em vista o risco de

\footnotetext{
${ }^{3} \mathrm{O}$ bairro foi construído durante a gestão do então prefeito Ronaldo Junqueira e do governador Francelino Pereira, e sua inauguração contou com contou com ampla presença das autoridades políticas da época. (GAZETA DO SUL DE MINAS, 25 de agosto de 1981).
} 
deslizamento por ser uma área de morros. Os moradores tinham que parar na atual Avenida Alcoa, e caminhar por quarteirões a fio enfrentando a lama nos pés e a chuva no corpo.

Segundo os moradores mais antigos, além da ausência de ruas em boas condições de tráfego e transporte público de péssima qualidade, o bairro contava com inúmeros problemas de infraestrutura. Inicialmente eram somente "casas e barro". Não havia hospital, posto de saúde, escola, creche, praças. Faltava água quase todos os dias, e era corriqueiro o transbordamento das fossas e consequentemente o esgoto correr a céu aberto pelas ruas, gerando enorme mau cheiro.

Nesse cenário a pode-se compreender que a cidade convive com a modernidade e o caos, áreas urbanisticamente corretas e áreas decadentes de infraestrutura, prédios suntuosos para o desfrute turístico e uma região marginalizada pelo poderio público. Periferia não é tão somente compreendida em relação de distância. É também evidenciada mediante a nítida desigualdade entre os moradores que ocupam o centro e os que moram na área periférica.

Socialmente, as periferias urbanas são áreas de concentração de moradias de população de baixa renda, carente dos serviços básicos essenciais e que sofrem os efeitos de longos deslocamentos para o trabalho, o consumo e o lazer. Reforçam o ciclo de pobreza cada vez mais difícil de romper. (MOURA, ULTRAMARI, 1996, p.11)

Afastados dos equipamentos públicos, os moradores do Conjunto Habitacional criaram uma "Associação de Bairro", dinamizando a história a partir dos conflitos de interesses. Se por um lado o interesse da classe dominante com a periferização é manter a classe popular distante da região central para que com o tempo e todo investimento estatal provoque-se uma especulação imobiliária em toda a área intermediária entre o centro e a periferia (MOURA, ULTRAMARI, 1996), por outro havia o interesse dos moradores em adquirir acesso aos bens de lazer, esporte, educação, saúde.

A moradora Joana ${ }^{4}$ lembra ainda hoje, e com muito entusiasmo, que a Associação liderou um grande panelaço pelas ruas do centro da cidade, passando em frente às casas comerciais da rua central da cidade e chegando até a prefeitura,

\footnotetext{
${ }^{4}$ Os nomes dos entrevistados são fictícios.
} 
diante da reivindicação de água. A entrevistada recorda que o então prefeito ${ }^{5}$ os recebeu cordialmente e não passou nem uma semana e vários caminhões pipa foram destinados até o bairro para suprir a necessidade da caixa d'água. É importante notar a satisfação da moradora em se sentir como colaboradora nas conquistas do bairro teve e o tom saudosista de uma comunidade pró-ativa.

As reivindicações da Associação estavam organizadas em diversas frentes: manifestação, denúncia escrita, denúncia oral e barganha política. A crítica escrita aparecia principalmente nas publicações do jornal "Dicas", jornal de circulação no bairro. Era comum, também, as lideranças da Associação, descontentes com alguma situação, irem à prefeitura reclamar.

Já a barganha adveio do entendimento das lideranças que, para adquirirem bens públicos, era necessário o estreitamento de laço com políticos de grande projeção na cidade, e nas suas falas, vários políticos são citados. Cientes de que muitos candidatos transformariam a área em reduto político, ou muitas vezes até com proximidades ideológicas com alguns partidos, a Associação se utilizou também da troca de favores, na qual se concedeu o apoio a determinadas candidaturas e se negociou melhorias para o bairro.

Uma das formas de fazer esse estreitamento foi mediante vários eventos culturais que a Associação promovia e convidava as autoridades políticas da época para prestigiarem. Como ilustração, a moradora Laura relata que realizavam desfiles da Rainha da Primavera, Concurso de Miss e um dia após o concurso, o prefeito da época, levou o pessoal para sua fazenda dele com direito a churrasco e canjiquinha. Ao perceber a animação dos moradores diante da piscina, conversou com o presidente de bairro, para construírem um complexo aquático - e isso foi feito.

É interessante notar que, embora carente de infraestrutura, já no início do bairro havia um posto policial. Das 17 entrevistas realizadas com moradores antigos, 16 apontam que o bairro era mais seguro antigamente e perguntando a uma das lideranças de bairro o motivo da existência de uma cadeia no bairro (se era para conter a violência), ele afirmou que o bairro não era violento, mas como recebeu gente de toda parte do país, o poder público implantou.

Morador Julio: Ninguém conhecia quase que ninguém, foi no início, era uma região de estrangeiros, veio gente do Brasil inteiro pra morar ali, de todas as

\footnotetext{
${ }^{5}$ Adnei Pereira de Morais (administração de 1986-1989).
} 
regiões. Eu não sei se por medida de segurança se tomaram essa atitude, eu não sei se foi por motivo político para mostrar que tinha poderio.

Esse mesmo morador frisa de forma bem crítica de que o bairro não tinha asfalto, nem hospital, mas posto policial tinha.

Pode-se conjecturar que não era violento por haver um posto policial que inibia o crime. Contudo, nas entrevistas percebeu-se a quão precária era a própria estrutura de segurança ao ponto de não haver viatura e poucos policiais. Portanto, haver uma delegacia no bairro não seria suficiente se não houvesse outros elementos.

O primeiro elemento que podemos refletir é a partir da fala da professora Sônia que mora no bairro desde o seu início e diz que antes "Não tinha briga, nem confusão, era um bairro de trabalhadores". De acordo com ela, "O bairro ficava sem ninguém durante o dia. A gente só voltava para dormir porque quase todo mundo trabalhava no centro". Isso é muito ilustrativo em se tratando de periferia, a qual se organiza sendo verdadeiros dormitórios de trabalhadores (MOURA, ULTRAMARI, 1996).

Contudo, além da identidade de serem trabalhadores, há outro indicativo de ser um local tranqüilo apesar das ausências estruturais. Na ausência do poder público criou-se uma rede de solidariedade entre os moradores, no qual algumas lideranças direcionaram atividades de união entre os residentes do bairro, seja através da política, do esporte ou da cultura. E em se tratando da política, o trabalho desenvolvido pela Associação foi a pedra de toque.

No esporte, no ano de 1981 foi criada a União Recreativa Casas Populares $^{6}$ (URCP). As vitórias não foram apenas registradas pelas medalhas e troféus de inúmeros campeonatos dentro e fora da cidade, mas no reconhecimento de ex-jogadores da importância de um trabalho comprometido para com o esporte.

Uma presença cultural fortíssima no bairro foi a organização de uma escola de samba comunitária, a União Imperial. Vários são os depoimentos, enfáticos, para contar as lembranças em relação a essa escola de samba, mas não cabem nestas páginas. O que é importante frisar para o presente trabalho é que o sentido comunitário era realmente levado a sério, seja nos ensaios, seja em cada morador doando uma parte do seu tempo e de seu trabalho nas costuras das

\footnotetext{
${ }^{6}$ Nomenclatura até hoje destinada ao bairro pelos seus moradores mais antigos e também os da cidade.
} 
fantasias, na construção dos carros alegóricos, ou empurrando-se o carro pela avenida principal da cidade. A escola tinha até mesmo um pátio onde se fazia festa "julina". Nesse local, lotava-se de barracas de guloseimas, apresentavam-se cantores custeados pela Secretaria de Cultura, havia quadrilhas e o até o pessoal do centro da cidade ia até lá comemorar. De acordo com um dos fundadores da escola de samba, esse perfil comunitário foi sendo esvaziado quando as pessoas começaram a cobrar pelo serviço, mediante comparação com o pagamento que escolas de grande porte realizavam em relação aos seus funcionários.

\section{A ESCOLA}

Foi neste cenário que a Escola Estadual Professor José Castro se estabeleceu. Com doação de terreno, pela prefeitura, do próprio Conjunto Habitacional, a escola esteve presente desde 1987 numa frágil e precária estrutura, formando os filhos dos trabalhadores e acompanhando o crescimento e as mudanças do bairro.

Professores mais antigos da escola relatam o quanto a estrutura era sucateada, ao ponto de haver frequentemente goteiras na sala de aula. Há fotos de certo período da escola que a biblioteca estava em desuso com inúmeros livros amontoados em mesas.

Não havia um local para a merenda e a refeição era servida nas próprias salas de aula. Eram apenas quatro salas de aula (hoje a escola conta com uma biblioteca, oito salas de aula, refeitório, horta, sala de informática, quadra). Mudanças de ordem física foram realizadas para atender o crescimento da demanda, tal como o bairro que cresceu em termos de estrutura para atender as exigências dos moradores.

Ainda sob a perspectiva de comparação e de certa extensão de características de um espaço para outro, o bairro era seguro no seu início a escola também era. Uma das fontes para se perceber isso foi através de fotos antigas da escola e a conversa com funcionários que estão a mais tempo na escola. Uma foto mostra que antes a escola não era murada, mas tinha uma cerca. As professoras mais antigas na escola relatarem que, embora no portão principal tivesse um enorme buraco, as crianças não fugiam e não havia furto. 
Em outra imagem obtida, é captado o ambiente de uma das salas de aula. No seu fundo encontra-se uma prateleira servindo de armário, em que a professora dispôs caixas encapadas com papel pardo (provavelmente as utilizava) para guardar materiais escolares para usufruto dos alunos. Intrigadas, as pesquisadoras perguntaram se não havia furtos, tendo em vista que hoje os armários têm cadeados e mesmo assim são danificados e furtados - e uma funcionária, que está na escola há mais de 12 anos disse que não tinha. Quando perguntada o porquê então a escola resolveu mudar os armários, ela afirmou que receberam a verba e então trocaram e diante do questionamento sobre o motivo dos desrespeitos em relação aos bens da escola ela alega eu acha que foram mudanças na família.

Na pesquisa a memória é entendida tendo por base Halbwachs (2006), na qual a memória permanece enquanto o grupo existir ou na memória de cada integrante. Daí a importância da relação entre os participantes. Para que se mantenha ativa a memória os sujeitos, esses precisam se aproximar, diante da necessidade do outro para contrapor, completar, reforçar e nessa relação entre o testemunho do eu e do outro que é possível a recordação coletiva.

Essa aproximação para a narrativa de diferentes pessoas que participaram da história do bairro e da escola tem contribuído para que lembranças surgissem, e que a relação sociocultural fosse estabelecida, numa leitura crítica de entendimento do espaço como reflexo de ordem política, econômica e cultural, e o conflito de interpretações como inerente do processo de polifonia diante das diversas perspectivas.

Nesse sentido, a professora Sônia, embora compartilhe de inúmeras memórias com a funcionária que está há 12 anos, tem uma perspectiva diferente quando assume que uma das razões do vandalismo na escola ocorrer atualmente seja porque tudo o que é muito fechado, de pouco acesso, tomado como algo estritamente privado, acaba sendo alvo de depredações.

Os muros não dividem apenas a escola dos moradores, os muros dividem cada propriedade. Se antes era recorrente a lembrança de ir para rua debaixo passando pela casa do vizinho, hoje a ex-moradora Luciene percebe que as pessoas vivem com medo e às vezes é até difícil lembrar onde os amigos moram, tendo em vista que não se vê mais as casas, mas apenas os muros.

Bauman (2009), compreendendo o espaço como um reflexo da globalização e a consequente individualização do espaço, afirma que: 
A intenção desses espaços vetados é claramente dividir, segregar, excluir, e não de criar pontes, convivências agradáveis e locais de encontro, facilitar as comunicações e reunir os habitantes da cidade. [...]) Mas, em lugar de defender a cidade e todos os seus habitantes de um inimigo externo, servem para dividir e manter separados seus habitantes: para defender uns dos outros, ou seja, daqueles a quem se atribuiu o status de adversários. (BAUMAN, 2009, p.42)

A separação entre os moradores, cada qual fechado no seu terreno privado, não ocorre apenas no âmbito territorial, mas simbólico. Se antes são recorrentes as memórias, seja no espaço do bairro ou da escola, de festas juninas, comemoração do aniversário do bairro, competições esportivas, reuniões de moradores, atualmente essa união foi se esgarçando. Junto dela fatiou-se a responsabilidade com o que é público.

Sob o lema de que "Cada um faz sua parte", há a ausência de tomada de responsabilidade no coletivo, no qual a comunidade poderia pensar em estratégias de preservação, de cuidado, de formas de cobrança e de denúncia. Isso é ilustrado na fala de Laura, uma antiga liderança do bairro. Ela afirma que com a Associação de Bairro conseguiram muita coisa, que as novas gerações além de não cuidarem, depredam, e não se mobilizam em lutar pelo bairro.

Se por uma lado houve conquistas estruturais para o bairro e para a escola, por outro lado os laços comunitários fragilizaram-se com o tempo. Diminuindo-se os espaços de convivência democrática, criou-se um terreno fértil para o medo e insegurança - não se conversa com o próximo, pois esse já não é tomado como tão próximo assim. Ao invés de criarem momentos de lazer e de fortalecimento da comunidade, percebe-se que houve uma individualização crescente resultando na depreciação com o espaço público, uma vez que esse os sujeitos não estão entrelaçados por laços de pertencimento a esse espaço, o que é perceptível nos 17 questionários respondidos pelos estudantes, dos quais apenas 6 apontam utilizar $65 \%$ ou mais dos espaços públicos do bairro, enquanto o restante utiliza $50 \%$ ou menos.

A ausência de participação comunitária na utilização dos equipamentos públicos resulta em relações mais vulneráveis e mais instáveis. Uma das preocupações apresentadas em muitos questionários em relação ao bairro foi a (in)segurança, e no que se refere à escola, o problema mais apontado foram as 
brigas. O curioso é que quando convidados a pensarem em possíveis soluções, a resposta quase que unânime é "mais controle, mais fiscalização".

\section{CONSIDERAÇÕES FINAIS}

O início da formação do bairro foi marcado por carências e ausências que se estenderam para o universo da Escola Estadual Professor José Castro de Araújo. Atualmente os antigos moradores fazem a comparação com tempos passados e percebem importantes mudanças, mas principalmente na nova geração se nota essa ausência com a leitura do passado, um enfraquecimento da noção de pertencimento e de apatia com o que é público.

Se antes moradores buscavam aproximação com políticos de grande poder de modo a conseguir bens para o bairro, atualmente apenas registra-se em boa parte dos espaços públicos do bairro os nomes daqueles que historicamente pertenceram à elite, perpetuando-se a versão histórica (e oficial) dos "vencedores". A história das minorias continua sucumbida e soterrada diante de uma geração que não conhece o chão onde pisa, exemplificada na pesquisa com 17 alunos dos $4^{\circ}$ anos em que todos afirmaram desconhecimento sobre a história do bairro, mesmo tal conteúdo geralmente ser ensinado no $2^{\circ}$ ou no máximo no $3^{\circ}$ ano do Ensino Fundamental.

Pulverizando-se a micro história não se reconhece o espaço, nem o que pessoas comuns fizeram por ele; não se valoriza as estratégias que foram anteriormente pensadas e nem se aperfeiçoa os mecanismos de luta. Por isso, deve-se pensar que a recuperação da história institucional e do bairro pode ser uma ferramenta para valorização da pluralidade de versões da comunidade, preservação do patrimônio escolar e fortalecimento da identidade local, buscando assim afirmar a história da camada popular e, no caso, sua relação com a Escola Estadual Professor José Castro de Araújo.

\section{REFERÊNCIAS}

ADMINISTRAÇÃO INAUGURA GINÁSIO E HOSPITAL NO CONJUNTO. Jornal da Cidade, Poços de Caldas, 05 set. 1991. 
ALBERTI, Verena. Obras coletivas de história oral. Tempo - Revista do Depto. de História da UFF, Rio de Janeiro, v.2, no 3, p.206-219, jun. 1997.

BAUMAN, Zygmunt. Confiança e medo na cidade. Rio de Janeiro: Zahar, 2009.

COSTA, da Epaminondas. Manual do Patrimônio Público - Teoria e Prática. Belo Horizonte: Inédita, 1999. (p.17 - 23).

FERREIRA, Jurandir. Um hectare na história de Poços de Caldas. Poços de Caldas: Gráfica Brasil, 1996.

Conjunto Habitacional "Dr. Pedro Affonso Junqueira" será inaugurado amanhã pelo Governador Francelino Pereira. Gazeta do Sul de Minas, Poços de Caldas, 22 ago. 1981.

Compradores das Casas Populares receberam as chaves das mãos do Governador Francelino Pereira. Gazeta do Sul de Minas, Poços de Caldas, 25 ago. 1981.

HALBWACHS, M. A memória coletiva. Trad. de Beatriz Sidou. São Paulo: Centauro, 2006. Citado por POLLAK, Michael. Memória, Esquecimento, Silêncio. Estudos Históricos. Rio de Janeiro, vol. 2, n. 3, 1989, p. 3-15.

LEAL, Luana Aparecida Matos. Memória, rememoração e lembrança em Maurice Halbwachs.

<http://www.letras.ufscar.br/linguasagem/edicao18/artigos/045.pdf>. Acesso em: 15 mar. 2016

MEGALE, Nilza Botelho. Memórias Históricas de Poços de Caldas. Poços de Caldas: Sul Minas, 2002.

MOURA, Rosa, ULTRAMARI, Clovis. O que é Periferia Urbana. São Paulo: Brasiliense, 1996.

SABALLA, Viviane. Educação Patrimonial, "Lugares de Memória”. Rev. Mouseion, v. 1, p. 23-25, jun. 2007.

SOUZA, Maria José de (Tita). Reinado e poder no Sul das Minas Gerais. Belo Horizonte: Mazza, 2015. 